\title{
AWARENESS OF DIABETES AND ITS COMPLICATIONS AMONG DIABETES PATIENTS AND THEIR CARE TAKERS ATTENDING A TERTIARY CARE HOSPITAL IN CHENNAI SUBURBAN AREA
}

\author{
Meenakshi Sundari Subramaniyan Natarajan'1, Annam Lakshmanan², Balaji Ramraj³ \\ ${ }_{1}^{1}$ Associate Professor, Department of General Medicine, SRM Institute of Science and Technology, Chennai, Tamilnadu, India. \\ 2Intern, Department of General Medicine, SRM Institute of Science and Technology, Chennai, Tamilnadu, India. \\ ${ }^{3}$ Associate Professor, Department of Social and Preventive Medicine, SRM Institute of Science and Technology, Chennai, Tamilnadu, \\ India.
}

\section{ABSTRACT}

\section{BACKGROUND}

Diabetes is a chronic metabolic disorder with increased morbidity and mortality. The aim of the study is to analyze and compare the level of awareness among the diabetic patients and their non-diabetic care takers. Even though various studies have analyzed the awareness levels of the disease and its complications in diabetic patients, there is yet a need to assess the awareness of the disease among the patients' care takers.

\section{METHODS}

It is a cross sectional study. A self-designed questionnaire was given to 500 study participants (both diabetic patients and their non-diabetic care takers) above the age of 18, attending the SRM Medical College Hospital and Research Center. The obtained data was assessed and compared by using SPSS Ver. 15.

\section{RESULTS}

Of all the diabetic patients, $47 \%$ knew about the disease process and causative factors and only $38 \%$ knew about its complications. Of the total non-diabetic care takers, $53 \%$ had the knowledge about the disease process and its cause and 39\% knew about the complications. p value was not significant in our study which implied both the groups were inadequately aware of the disease and its complications.

\section{CONCLUSIONS}

The level of knowledge and awareness about diabetes and its complications is insufficient in both patients and their care takers which indicates the need to educate them about the disease to combat the morbidity and mortality of the disease.

\section{KEY WORDS}

Diabetes Mellitus, Complications of Diabetes, Awareness, Care Takers

HOW TO CITE THIS ARTICLE: Natarajan MSS, Lakshmanan A, Ramraj B. Awareness of diabetes and its complications among diabetes patients and their care takers attending a tertiary care hospital in Chennai suburban area. J. Evolution Med. Dent. Sci. 2019;8(23):1839-1842, DOI: 10.14260/jemds/2019/404

\section{BACKGROUND}

The contemporary era has seen a sudden surge in the occurrence of the metabolic disorder- diabetes mellitus. The foremost aetiology for the increase in the number of cases of diabetes is the trending sedentary lifestyle and change in the dietary patterns of the people.[1] According to the International Federation of Diabetes, the number of adults around the world who are suffering from diabetes is 425 million, and the numbers are expected to reach around 629 million by $2045 .{ }^{[2]}$ In India, an estimated $8.8 \%$ adults are diagnosed with diabetes with the proportion of males $(7.1 \%)$ being higher than females (6.8\%).[3] The prevalence of the disease in Tamil Nadu is $16.1 \%$ which is relatively high when compared to other states in India.[3]

\section{'Financial or Other Competing Interest': None.}

Submission 14-04-2019, Peer Review 25-05-2019,

Acceptance 31-05-2019, Published 10-06-2019.

Corresponding Author:

Meenakshi Sundari, Subramaniyan Natarajan,

Associate Professor,

Department of General Medicine,

SRM MCH and RC, Kattankulathur,

Kanchipuram-603203,

Tamilnadu, India.

E-mail: dr.meenakshisundari@gmail.com

DOI: $10.14260 / j e m d s / 2019 / 404$

High risk individuals include people more than 45 years of age, hypertensive people,[4] obesity,[5] family history of diabetes,[6] dyslipidaemia.[7] Crucial factors which affect the quality of life of a patient suffering from diabetes include disease awareness, early detection and screening and quality of treatment.

Complications of diabetes affect major systems in the body such as ocular, cardiac, renal, nervous system and skin complications.[8] The macro vascular complications of diabetes include stroke, transient ischemic attacks, coronary heart disease and peripheral vascular disease. The micro vascular complication includes diabetic retinopathy, diabetic nephropathy and diabetic neuropathy. Other complications include cataract, glaucoma, depression, foot ulcers (Due to neuropathy and peripheral vascular disease), emergencies like diabetic ketoacidosis, hyperosmolar coma, hypoglycaemia. The symptoms of hypoglycaemia include anxiety, tremors, sweating, palpitations, excessive hunger, light headedness, confusion and coma. Knowledge about diabetes and its complications enhances the personal disease handling skills among the individuals. [9] Degree of awareness was higher among patients who had interactions with health professionals or diabetic counsellors which makes up about $22.3 \%$ of the total diabetic patients.[10] This number has to significantly improve to curb the challenge of the global epidemic of diabetes. 
Increasing awareness of the disease and treatment of the disease will pave way for developing an educated diseasefree future population. Awareness about the disease, its risk factors and its complications is essential for improving treatment and reducing the morbidity and mortality rates. This study focuses on performing a statistical analysis of the awareness of diabetes and its complications among the diabetic patients and their non-diabetic care takers as they help in assisting and motivating the patient in their day to day life. This study will help us to analyze the current scenario of awareness of Diabetes and its Complications. Low awareness among the people is an indicator for the need to educate them about the disease. This will aid in improving their compliance to treatment and lifestyle modifications which in turn helps in the reduction of the morbidity and mortality of the disease. Thus, helping to conquer the diabetes epidemic.

\section{METHODS}

This is a cross-sectional questionnaire-based study. The study subjects included the diabetic patients and their non-diabetic care takers above the age of 18 attending the SRM medical college hospital and Research center and who have given the consent to participate in the study. Patients below 18 years were excluded. The Institutional Ethical Committee clearance from the college was obtained. The sample size was calculated with the help of the statistician and a total of 500 participants were included in the study. A structured selfdesigned questionnaire was handed over to the study participants. The self-designed questionnaire is formulated in two languages, one in English and the other in the regional language (Tamil). The questions were read to the patients in basic terms if the patient was unable to read.

Sample size was taken based on the conveniences of the study.

Study was done by convenient sampling technique. The patients were selected by convenience sampling technique.

\section{Statistical Analysis}

The collected data was entered in Microsoft excel and analyzed using SPSS version 15. Categorical data was summarized as frequencies with \%. Chi square test was used to compare the awareness levels of the disease between the patients and their care takers. A p value of $<0.05$ was considered statistically significant.

\section{RESULTS}

The size of our study population and 500 subjects which consisted of 141 diabetic patients 359 non-diabetic care takers. The participants were given a self-designed questionnaire and the answers were evaluated to know the level of awareness of the disease in that region. The questionnaire consisted of questions which ranged from basic information about diabetes up to complications of the disease. The study population was collected from General Medicine Outpatient Department and Inpatient ward. 288 males and 212 females participated in our study, their ages varied from 18 and above and they belonged to the education qualifications such as primary, high school, undergraduate and post graduate. The interpretation on the awareness levels is summarized in the table as percentage.

\begin{tabular}{|c|c|c|c|c|}
\hline Awareness & $\begin{array}{c}\text { Diabetes } \\
(\mathbf{N}=141)\end{array}$ & $\begin{array}{c}\text { Non-Diabetes } \\
\text { (N=359) }\end{array}$ & $\begin{array}{c}\text { Chi } \\
\text { Square }\end{array}$ & p Value \\
\hline $\begin{array}{c}\text { Knowledge about } \\
\text { Glucose levels in } \\
\text { Diabetes }\end{array}$ & $115(81.56)$ & $316(88.02)$ & 3.55 & 0.059 \\
\hline $\begin{array}{c}\text { Awareness about the } \\
\text { nature of the Disease }\end{array}$ & $16(11.34)$ & $96(26.74)$ & 13.80 & 0.0002 \\
\hline $\begin{array}{c}\text { Awareness about the } \\
\text { symptoms of diabetes }\end{array}$ & $14(9.92)$ & $49(13.64)$ & 1.27 & 0.259 \\
\hline $\begin{array}{c}\text { Awareness about } \\
\text { frequency of checking } \\
\text { blood glucose }\end{array}$ & $112(79.43)$ & $257(71.58)$ & 3.22 & 0.073 \\
\hline $\begin{array}{c}\text { Awareness about the age } \\
\text { of initial screening of } \\
\text { diabetes }\end{array}$ & $78(55.31)$ & $202(56.26)$ & 0.037 & 0.463 \\
\hline $\begin{array}{c}\text { Awareness about } \\
\text { diabetic counseling }\end{array}$ & $66(9.92)$ & $148(41.22)$ & 1.289 & 0.150 \\
\hline $\begin{array}{c}\text { Awareness about the } \\
\text { immunity levels in } \\
\text { diabetes }\end{array}$ & $112(79.43)$ & $257(71.58)$ & 3.22 & 0.073 \\
\hline \multicolumn{4}{|l|}{ Table 1. Awareness About Diagnosis and Treatment of Diabetes } \\
\hline
\end{tabular}

\begin{tabular}{|c|c|c|c|c|}
\hline Awareness & $\begin{array}{l}\text { Diabetes } \\
(\mathrm{N}=141)\end{array}$ & $\begin{array}{c}\text { Non-Diabetes } \\
(\mathrm{N}=359)\end{array}$ & $\begin{array}{c}\text { Chi } \\
\text { Square }\end{array}$ & $\begin{array}{c}\text { p } \\
\text { Value }\end{array}$ \\
\hline $\begin{array}{c}\text { Awareness about } \\
\text { cardiac complications }\end{array}$ & $56(39.7)$ & $135(37.60)$ & 0.19 & 0.662 \\
\hline $\begin{array}{c}\text { Awareness about renal } \\
\text { complications }\end{array}$ & 12 (8.51) & 48 (13.37) & 2.26 & 0.132 \\
\hline $\begin{array}{c}\text { Awareness about } \\
\text { diabetes in pregnancy }\end{array}$ & 53 (37.58) & 140 (38.99) & 0.08 & 0.771 \\
\hline $\begin{array}{l}\text { Awareness about eye } \\
\text { complications }\end{array}$ & $20(14.10)$ & 140 (38.99) & 4.94 & 0.026 \\
\hline $\begin{array}{c}\text { Aware ness about gastric } \\
\text { complication }\end{array}$ & $66(46.80)$ & $148(41.22)$ & 1.289 & 0.150 \\
\hline $\begin{array}{c}\text { Awareness about } \\
\text { vascular complication }\end{array}$ & 32 (22.69) & 101 (28.13) & 1.53 & 0.216 \\
\hline $\begin{array}{l}\text { Awareness about mental } \\
\text { health issues in Diabetes }\end{array}$ & 25 (17.73) & 64 (17.82) & 0.001 & 0.546 \\
\hline $\begin{array}{l}\text { Awareness about sexual } \\
\text { dysfunction in Diabetes }\end{array}$ & 19 (13.47) & 73 (20.33) & 3.17 & 0.075 \\
\hline $\begin{array}{l}\text { knowledge about foot } \\
\text { care in diabetes }\end{array}$ & 107 (75.88) & $273(76.04)$ & 0.00 & 0.970 \\
\hline $\begin{array}{c}\text { Awareness about } \\
\text { delayed wound healing }\end{array}$ & 104 (73.5) & 257 (71.58) & 0.24 & 0.626 \\
\hline $\begin{array}{c}\text { Awareness about stroke } \\
\text { in Diabetes }\end{array}$ & $63(44.68)$ & $134(37.32)$ & 2.29 & 0.130 \\
\hline $\begin{array}{c}\text { Awareness about } \\
\text { peripheral neuropathy }\end{array}$ & $94(66.66)$ & $184(51.25)$ & 9.74 & 0.002 \\
\hline $\begin{array}{c}\text { Awareness about } \\
\text { increased risk of } \\
\text { infections like UTI/TB. }\end{array}$ & $46(32.62)$ & $122(33.98)$ & 0.08 & 0.772 \\
\hline
\end{tabular}

\begin{tabular}{|c|c|c|c|c|}
\hline Gender & Mean & SEM & T test & p Value \\
\hline Male & 8.45 & 0.15 & 0.196 & 0.844 \\
\hline Female & 8.40 & 0.20 & & \\
\hline \multicolumn{4}{|c|}{ Table 3. Comparison of Awareness of Diabetes } \\
Between Male and Female Subjects \\
\hline
\end{tabular}

\begin{tabular}{|c|c|c|c|c|}
\hline Parameters & Mean & Sem & ANOVA & p Value \\
\hline Illiterate & 7.16 & 0.53 & & \\
\hline Primary School & 7.85 & 0.35 & 4.926 & 0.001 \\
\hline High School & 8.30 & 0.17 & & \\
\hline U.G & 8.80 & 0.20 & & \\
\hline P.G & 9.47 & 0.42 & & \\
\hline \multicolumn{6}{|l}{ Table 4. Awareness of Diabetes with Respect to Education } \\
\hline
\end{tabular}




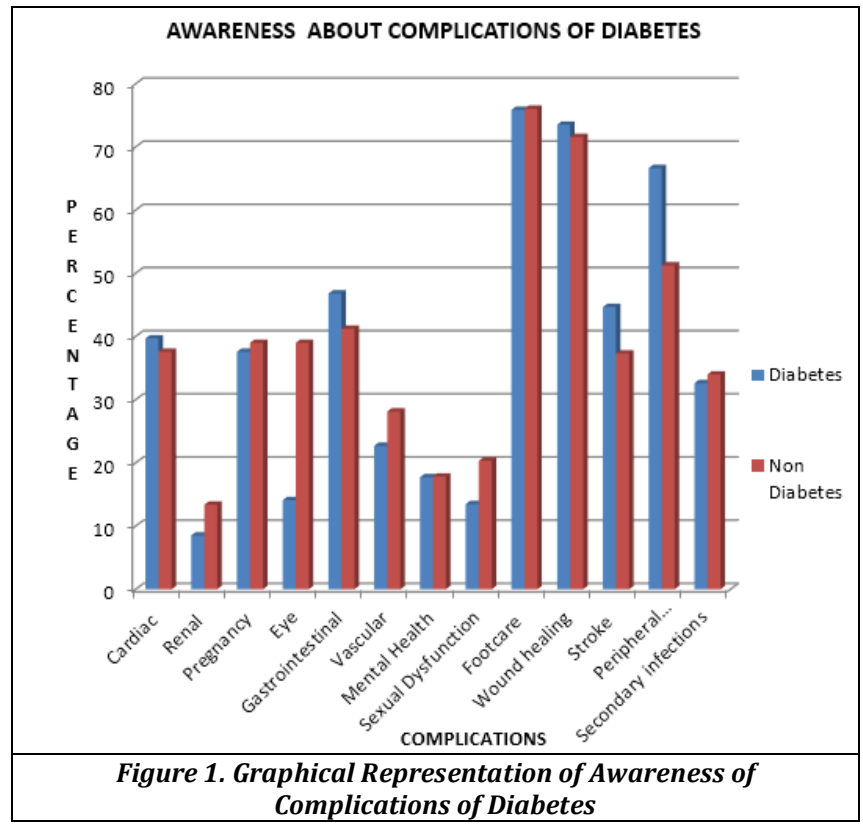

$81.56 \%$ of total diabetes patients $88.02 \%$ of non-diabetes mellitus knew about the cause of diabetes, whereas $88.66 \%$ of diabetes and $73.26 \%$ of non-diabetes people were unaware that diabetes mellitus is a chronic disease which cannot be cured but can be gotten under control. Hypoglycemic symptoms such as tremors, giddiness, sweating are commonly mistaken as hyperglycemic symptoms which is clearly indicated by our study which showed that $90.07 \%$ of diabetes and $86.35 \%$ of non-diabetes have this misconception. Knowledge on the correct frequency of checking blood sugar levels was known by $79.34 \%$ of diabetes mellitus and $71.58 \%$ of non-diabetes patients. $70.21 \%$ of diabetes mellitus and $76.32 \%$ of non-diabetes mellitus are unaware about the correct screening age for diabetes in India which is above 30 years of age. Diabetic counseling can greatly motivate the patients towards a healthy life; ironically $89.39 \%$ of diabetes mellitus and $72.98 \%$ of non-diabetes are unaware about the existence of diabetic counseling. This shows that there is a rampant need to spread awareness which will help to fight the long battle against diabetes. The strong correlation between immunity and diabetes was known by $72.34 \%$ of diabetes and $77.71 \%$ of non-diabetes people.

Knowledge about the long-term complications of diabetes is shown in Table 2 . The most common complication reported by the diabetic population is that the participants knew the importance of foot care (75.88\%) which indicates that many people were well aware and had encountered the foot complications. The awareness levels of other complications were as follows; delayed wound healing (73.75\%), peripheral neuropathy (66.6\%), stomach disorders (46.80\%), stroke (44.68\%), cardiac (39.71\%), secondary infections (32.62\%), vascular complications (22.69\%), mental health issues (17.73\%), eye involvement (14.18\%), sexual dysfunctions (13.47\%) and kidney disease (8.8\%). Among the non-diabetic the percentage of awareness reported were delayed wound healing $(71.58 \%)$, peripheral neuropathy (51.25\%), stomach disorders (41.22\%), cardiac (37.60\%), stroke (37.32\%), secondary infections (33.98\%), vascular complications (28.1\%), eye involvement (23.11\%), sexual dysfunction (20.33\%), mental health issues (17.82\%), kidney disease
(13.37\%). The situation is very grim because even the diabetes patients have very poor knowledge about the complications of the disease. The most important complication which is chronic kidney disease is known to a very less proportion of people as many people would be diagnosed with this complication in the later stage of the disease which would prove fatal in the end. Of the total diabetic populations $47 \%$ of them knew about the disease process and its cause and $38 \%$ of them knew about the complications. Of the total non-diabetic care takers $53 \%$ knew about the disease process and 39\% knew about the complications. $\mathrm{P}$ value turned out to be insignificant which means that both the study subjects were inadequately aware of the disease and its complications.

\section{DISCUSSION}

A study conducted by M.A HOQUE et al[11] showed the most acquainted complication in diabetes was cardiac disease (48.9\%), another study by Kavitha. $\mathrm{M}$ et al[12] showed that only $10 \%$ of diabetic patients were aware about foot complications, whereas in our study the importance of foot care was known to $75.88 \%$ of the diabetes and $76.04 \%$ of the non-diabetes. Peripheral vascular disease causes narrowing of blood vessels increasing the risk of reduced blood flow in legs thereby causing delayed wound healing and gangrene formation. Study done by Yaa obirikiorang et al[13] reported that $51.5 \%$ of the diabetic population was aware about the foot complication in diabetes which was the most common complication in his study.

Our study focuses not just on the awareness among the diabetic population but also the care providers of diabetes population which was not done by the above-mentioned studies. Care takers play a vital role in motivating and taking keen care of the diabetes patients. So, knowledge about the disease and its complication should equally be known to care providers as well as patients suffering from the disease.

Awareness of the disease not only enlightens the patients and their attenders the knowledge about the disease but also provides a step to prevent the disease and its complications. The various levels of prevention of this chronic disease include primordial prevention, primary prevention, secondary prevention and tertiary prevention. Primordial and primary prevention mainly focuses on preventing the onset of the disease before it has actually occurred and also aims at reducing the risk factors of the disease, which includes avoiding alcohol use, usage of oral contraceptives pills, eliminating diets which increase cholesterol and triglycerides levels. Secondary prevention mainly pays attention to the diagnosed diabetes population, where proper and adequate management is required to withhold the complications. It includes maintenance of ideal body weight and maintaining blood glucose within normal range, regular intake of oral hypoglycemic drugs and insulin, routine checking of blood pressure, visual acuity and examination of feet for any defective blood circulation, loss of sensation and ulcers. All these measures are important as proper management of diabetes reduce the development of complications. Tertiary prevention is an intervention that is given during the late pathogenesis stage of the disease. The tertiary prevention is given after the onset of complications such as blindness, kidney failure, coronary heart disease, gangrene of the lower extremities etc. The most important 
aim is to reduce the suffering, development of impairments and disabilities and also to enhance the living condition of the individual. This prevention is possible with variety of professionals like physiotherapists, occupational therapists, speech therapists assisting the physicians.

Age and gender had no significance in our study with respect to the awareness of diabetes and its complications, but it was found that educational status of an individual does play a great significance in raising knowledge about the disease and its complications. The biggest setback for fruitful health education is Illiteracy. Education and knowledge about the disease at the right time can minimize the end result of the disease. Similar studies conducted by M. Deepa et al states that the highest score was secured by the professionals and that the mean percent score showed a rise with increased level of education. Another study conveys that education had a predominant role in keeping correct blood glucose.[11] These findings coincide with our results.

\section{CONCLUSIONS}

Diabetes mellitus is growing at an alarming rate and is soon on its way to become the most common disease of the millennial world. Although India is known as the diabetic capital of the world, it is very surprising to see such low levels of awareness among the people. Existing data suggests that this is the first study which reports the levels of awareness among both patients and their care takers. The results indicate abysmal awareness among the people. Raising awareness is the first major step in the combat against diabetes. This must begin with the members of the health care community including doctors, nurses, social workers etc. Doctors can play a major role in spreading awareness by counseling both diabetic and non-diabetic people. Doctors must maintain a healthy rapport with the patient which will ensure the patient comfort. This will result in patients overcoming their inhibitions and freely asking doctors queries to learn more about the disease. Individually, it is important for the diabetes patients to stay motivated, encouraged and utmost committed to steps that would benefit diabetes management. Interactive videos, posters, pamphlets, information sessions are various steps that could be taken to spread awareness among the public population. Social media is a powerful tool with a wide reach and can be used as a medium to gain appropriate knowledge about the disease. Raising awareness will help the public to inculcate new lifestyle changes which will help in bringing down the incidence of the disease in the near future.

\section{ACKNOWLEDGEMENT}

We extend our gratitude to the Dean and Management of SRM Medical Hospital and Research Center for allowing us to successfully conduct and complete our study.

\section{REFERENCES}

[1] Healy GN, Wijndaele K, Dunstan DW, et al. Objectively measured sedentary time, physical activity and metabolic risk: The Australian Diabetes, Obesity and Lifestyle Study (AusDiab). Diabetes Care 2008;31(2):369-71.

[2] International Diabetes Federation, IDF diabetes atlas $8^{\text {th }}$ edition (online) 2018. URL: http://www.diabetesatlas.org/across-the-globe.html

[3] Akhtar SN, Dhillon P. Prevalence of diagnosed diabetes and associated risk factors: evidence from the large scale surveys in India. J Soc Health Diabetes 2017;5:28-36.

[4] Kim MJ, Lim NK, Choi SJ, et al. Hypertension is an independent risk factor for type 2 diabetes: the Korean genome and epidemiology study. Hypertens Res 2015;38(11):783-9.

[5] Mokdad AH, Ford ES, Bowman BA, et al. Prevalence of obesity, diabetes and obesity-related health risk factors, 2001. JAMA 2003;289(1):76-9.

[6] Harrison TA, Hindorff LA, Kim H, et al. Family history of diabetes as a potential public health tool. Am J Prev Med 2003;24(2):152-9.

[7] Chen GY, Li L, Dai F, et al. Prevalence of and risk factors for type 2 diabetes in hyperlipidemia in china. Med Sci Monit 2015;21:2476-84.

[8] Papatheodorou K, Papanas N, Banach M, et al. Complications of Diabetes 2016. J Diabetes Res 2016;2016:6989453.

[9] Mahmood K, Akhtar ST, Haider I, et al. Dietary misconceptions in Pakistani diabetic patients. Pak J Med Assoc 2011;27(1):128-32.

[10] Rahman UZ, Irshad M, Khan I, et al. A survey of awareness regarding diabetes and its management among patients with diabetes in Peshawar, Pakistan. J Post Med Inst 2014;28(4):372-7.

[11] Hoque MA, Islam MS, Khan MAM, et al. Knowledge of diabetic complications in a diabetic population. J Med 2009;10(2):90-3. doi:10.3329/jom.v10i2.2821.

[12] Kavitha M, Aruna S. Knowledge on complications of diabetes mellitus among patients with diabetes mellitus - a descriptive study. Int J Compr Nurs 2014;1(1):18-20.

[13] Obirikorang Y, Obirikorang C, Anto EO, et al. Knowledge of complications of diabetes mellitus among patients visiting the diabetes clinic at Sampa Government Hospital, Ghana: a descriptive study. BMC Public Health 2016;16:637. 